This is an electronic reprint of the original article. This reprint may differ from the original in pagination and typographic detail.

Author(s): Tervo, Hannu

Title: $\quad$ Centres and peripheries in Finland: Granger causality tests using panel data

Year: $\quad 2009$

Version:

Please cite the original version:

Tervo, H. (2009). Centres and peripheries in Finland: Granger causality tests using panel data. Spatial Economic Analysis, 4, 377-390.

https://doi.org/10.1080/17421770903317652

All material supplied via JYX is protected by copyright and other intellectual property rights, and duplication or sale of all or part of any of the repository collections is not permitted, except that material may be duplicated by you for your research use or educational purposes in electronic or print form. You must obtain permission for any other use. Electronic or print copies may not be offered, whether for sale or otherwise to anyone who is not an authorised user. 


\title{
Centres and peripheries in Finland: Granger causality tests using panel data* $^{*}$
}

\begin{abstract}
Despite their importance from a policy point of view, empirical studies on the effects of growth centres in their regions are rare. This paper analyses mutual relationships between growth processes in centres and their surrounding hinterlands in nineteen Finnish regions. Annual population data from the period 1970-2004 are used. A novel testing procedure based on an extension of the Granger causality definition in a panel data context is applied. Heterogeneity between regions is allowed. Both the homogeneous non-causality hypothesis and the homogeneous causality hypothesis are rejected. Causal processes prove to be heterogeneous. Causality from centres to peripheries is found for nine regions and causality from peripheries to centres for twelve regions. Rapidly growing and large centres, in particular, have negative effects on their hinterlands.
\end{abstract}

Key words: regional growth; core-periphery; growth centre; Granger causality; panel data

JEL-codes: R11, O18, C23, C12

* Acknowledgements - This research has been undertaken with the support of the Academy of Finland, research project 120185. The author wishes to thank the unknown referees of this journal and session participants at the $48^{\text {th }}$ European Congress of the Regional Science Association International (Liverpool, 2008) and at the $54^{\text {th }}$ Annual North American Meetings of the Regional Science Association International (New York, 2008) for several valuable comments and suggestions relating to the paper. 


\section{Introduction}

An important regional policy question in all developed economies is whether it is appropriate to support regional centres as the way to develop lagging hinterland regions. Does the support to centres spread economic growth to hinterlands, or does it rather prevent growth there by creating negative effects? Large sums of money are devoted to such regional policies throughout the world without knowing their channels of effect or even whether the effects are positive or negative. Despite the theoretical arguments, empirical work designed to test these hypotheses has been rare (cf. Henry et al., 1997; Schmitt and Henry, 2000; Henry et al., 2001; Partridge et al., 2007; Partridge et al., 2008; Tervo, 2008). This paper examines the nature of the regional concentration process in Finland by analysing the relationship between the development of centres and hinterlands in 1970-2004. The aim is to introduce a novel and simple approach for analysing causal processes in regional growth.

The new economic geography (henceforth, NEG) predicts strong concentration of spatial growth (e.g., Fujita, Krugman and Venables, 1999; Fujita, 2007). The NEG emphasises the endogenous agglomeration forces generated through the three-way interactions between increasing returns, transport costs (broadly defined) and worker migration. Growth will become locked in at some location, where the growth rate will then increase. The process of cumulative causation takes over. Agglomeration or centripetal forces may involve market size linkages, thick labour markets and linkages through the creation and transfer of knowledge (Krugman, 1998; Fujita, 2007). However, alongside these forces, there are also opposing forces, i.e., centrifugal or dispersion forces, which may include congestion and other pure external diseconomies, immobile factors and land rents. The observed spatial configuration of economic activities is considered to be the outcome of a process involving both types of forces.

The idea of cumulative growth is by no means a new one; it is very much a recycling of ideas familiar to regional science. Myrdal (1956) spoke of circular and cumulative causation, Hirchman (1958) of forward and backward linkages, and Perroux (1955) of 
growth poles. At a later time, Pred (1966) associated these concepts of the 1950s still more explicitly with regional growth, and Kaldor (1970), together with Dixon and Thirlwall (1975), on the basis of these ideas presented a model emphasising the cumulative nature of the growth process. Traditional theories in regional science offer two hypotheses about the role of growth centres in regional growth and the relationship of centres to peripheries. According to these theories, growth centres may have both favourable and unfavourable effects on their hinterlands (e.g., Richardson, 1978; Parr, 1999a, 1999b). The net spillover effects may be either positive or negative. First, a growth centre may have "backwash" or "polarisation" effects as resources, especially labour, gravitate towards the centre. This is how things are conceived in Krugman's (1991) original core-periphery model: the stronger the mobility of labour, the stronger the process of cumulative causation, which results in a distinct core-periphery structure. The earlier literature implies that backwash effects are initially high and become weaker over time. As Richardson (1978, p. 170) writes, “...many backwash effects are of a 'one-shot' nature, e.g., the relocation of pre-existing industry from the hinterland to the pole, the inmigration of the skilled and educated, the transfer of past savings and so on". Second, a growth centre may have "spread" or "trickling down" effects on its hinterland due to the relocation of manufacturing plants, the decentralisation of population and the spread of innovation, investment and positive attitudes to growth (Richardson, 1978). Centrifugal forces in the NEG models represent this possibility. The earlier literature suggests that the time-horizon for these spread effects may be long.

Regional development has been centralised in Finland. Therefore, an important aim in present regional policy is to spread growth more evenly across the country by strengthening provincial towns (Tervo, 2005). According to this goal, each region (NUTS Level 3) should have a vigorous centre; however, there is much variation in the extent to which this has been realised at present. Only some regions have real growth centres. The growth of provincial towns in Finland has fostered growth in their immediate neighbouring municipalities, with the result that today the leading subregions form functional areas in each region. Rural areas within daily commuting distance have benefited when the growth has "spread" to the hinterlands (cf. Partridge et al. 2007). But 
has this development also benefited more remote municipalities and subregions in the region? Does the growth of regional centres (or present-day leading sub-regions) have effects on economic development in their hinterlands, and if they do, are these effects negative or positive? Conversely, does economic development in the hinterlands have any effects on the growth of the centres? An example of such an effect would be if people in the hinterlands were forced to leave their home area due to weak employment and living prospects. Finally, are these causal processes homogeneous throughout Finland, or do they vary across regions?

In order to test the relative importance of various effects, the Granger non-causality method in a panel framework is applied. Granger tests are increasingly being used to evaluate causal relationships in panel data. Panel Granger tests are significantly more efficient than conventional Granger tests (Baltagi, 2005; Hurlin and Venet, 2001, 2005; Hood III et al., 2008). A potential flaw shared by many analyses, however, is an inappropriate assumption of causal homogeneity. The literature based on early work by Hsiao (1986) and Holtz-Eakin et al. (1988) largely ignores the possibility of heterogeneity. A causal relationship may be present only in a subset of cross-sections and not in others. In our case, causality may, in particular, vary according to the size and rapidity of the growth of the centre. To be able to deal with the problem of heterogeneity, we employ the Hurlin and Venet $(2001,2005)$ procedure, in which four distinct scenarios are identified to describe the possible causal processes: homogeneous non-causality, homogeneous causality, heterogeneous causality and heterogeneous non-causality. The empirical analysis in this paper is based on annual population data from the period 19702004. Population data offer a reasonably good basis for the analysis of regional development in the long term.

The paper is organised as follows. Section 2 presents the methodology. Section 3 describes the data and the implementation of the study. Section 4 presents the results and Section 5 concludes.

\section{Employing Granger causality tests in a panel framework}


To address the existence of causality, the nature of the relationship between population growth in centres and peripheries is evaluated. Evaluating the character of the causal relationship between two variables is, of course, problematic. A standard tool used in econometrics is the Granger technique, which can, at any rate, be used as a first step in this evaluation. In the case of two variables, say $x$ and $y$, the first variable, $x$, is said to cause the second variable, $y$, in the Granger sense if the forecast for $y$ improves when lagged values for $x$ are taken into account (Granger, 1969). By estimating an equation in which $\mathrm{y}$ is regressed on lagged values of $y$ and lagged values of $x$, we can evaluate the null hypothesis that $x$ does not Granger-cause $y$. If one or more of the lagged values of $x$ is significant, we can reject the null hypothesis that $x$ does not Granger-cause $y$.

The introduction of a panel data dimension permits the use of both cross-sectional and time series information to test causality relationships, which apparently improves the efficiency of Granger causality tests (Baltagi, 2005; Erdil and Yetkiner, 2008). Granger tests can generate significant results with shorter time periods as the number of observations increases. Following Hurlin and Venet (2001; see also Hood III et al., 2008; Erdil and Yetkiner, 2008), we consider the variables to be covariance stationary, observed for $\mathrm{T}$ periods and $\mathrm{N}$ cross-section units (which consist of regions in our case). For each cross-section unit $i \varepsilon[1, \mathrm{~N}]$, the variable $x_{i, t}$ causes $y_{i, t}$ if we are better able to predict $y_{i, t}$ when using all the available information than when using only some of it.

Let us consider a time-stationary VAR representation, adapted to a panel context. For each cross-section unit $i(i=1, \ldots, \mathrm{N})$ and time period $t(t=1, \ldots, \mathrm{T})$ we have

$$
y i, t=\sum_{k=1}^{p} \gamma^{(k)} y_{i, t-k}+\sum_{k=1}^{p} \beta_{i}^{(k)} x_{i, t-k+v i, t,}
$$

where $v_{i, t}=\alpha_{i}+\varepsilon_{i, t}$ are i.i.d. $\left(0, \sigma_{\varepsilon}^{2}\right)$ and $p$ is the number of lags. The autoregressive coefficients $\gamma^{(k)}$ and the regression coefficients slopes $\beta_{i}^{(k)}$ are assumed constant for all lag orders $k \varepsilon[1, p]$. It is also assumed that $\gamma^{(k)}$ are identical for all units, whereas $\beta_{i}^{(k)}$ are 
allowed to vary across individual cross-sections. This is a panel data model with fixed coefficients. It is also possible to extend the model for the instantaneous case, which includes the current value of $x_{i}$ as a regressor.

Employing conventional Granger tests with panel data is not unproblematic. These problems may be caused by heterogeneity between the cross-section units. The first potential type of cross-section variation is due to distinctive intercepts. This variation is addressed with a fixed effects model in which heterogeneity is controlled by the introduction of individual effects $\alpha_{i}$. Another basis for heterogeneity is caused by heterogeneous regression coefficients $\beta_{i}^{(k)}$. This is a more problematic situation than the first one, and requires a more complex analytical response. If we consider model (1), the general definitions of causality imply testing for linear restrictions on these coefficients. The procedure has three main steps which are related to the homogeneous non-causality, homogeneous causality, heterogeneous causality and heterogeneous non-causality hypotheses.

The homogeneous non-causality (HNC) hypothesis implies the non-existence of any individual causality relationships. In model (1), the corresponding test is defined by

$$
\begin{aligned}
& H_{o}: \beta_{i}{ }^{(k)}=0 \forall \mathrm{i} \in[1, \mathrm{~N}], \forall \mathrm{k} \in[1, \mathrm{p}] \\
& H_{1}: \exists(\mathrm{i}, \mathrm{k}) / \beta_{i}{ }^{\left({ }^{2}\right)} \neq 0 .
\end{aligned}
$$

For testing $N p$ linear restrictions in (2), the following Wald statistic is computed:

$$
F_{H N C}=\frac{\left(R S S_{2}-R S S_{1}\right) / N p}{R S S_{1} /(N T-N(1+p)-p)},
$$

where $R S S_{2}$ denotes the restricted sum of squares residuals obtained under $\mathrm{H}_{\mathrm{o}}$ and $R S S_{1}$ corresponds to the residual sum of squares of model (1). If the individual effects $\alpha_{i}$ are assumed to be fixed, the sum of squared residuals are obtained from the maximum likelihood estimation (MLE), which in this case corresponds to the fixed effects (FE) 
estimator. It has been shown that the FE estimator is biased in the case where $\mathrm{T}$ is small (Nickell, 1981), but the bias decreases with T. We favour the FE estimator, since the bias may not be large and its use enables us to follow the testing procedure. Accordingly, the testing procedure can be implemented using the constrained regression technique (Hurlin and Venet, 2001; Hood III et al, 2008). No particular panel estimation is needed to compute the test statistics. Interpretation of the statistic relies on the Fischer distribution with $N p$ and $(N T-N(1+p)-p)$ degrees of freedom.

If the HNC hypothesis is rejected, the next step is to test the hypothesis of homogeneous causality (HC). The $F_{H C}$ test statistic is calculated using the sum of squared residuals from the unrestricted model described above $\left(R S S_{l}\right)$ and the sum of squared residuals $\left(R S S_{3}\right)$ from a restricted model in which the slope terms are constrained to equality for all the panel members in the sample. Thus, the hypotheses are

$$
\begin{aligned}
& H_{o}: \forall \mathrm{k} \in[1, \mathrm{p}] / \beta_{i}^{\left({ }^{(k)}\right.}=\beta^{(k)} \forall \mathrm{i} \in[1, \mathrm{~N}] \\
& H_{1}: \exists \mathrm{k} \in[1, \mathrm{p}], \exists(\mathrm{i}, \mathrm{j}) \in[1, \mathrm{~N}] / \beta_{i}^{\left({ }^{(k)}\right.} \neq \beta_{j}{ }^{(k)},
\end{aligned}
$$

and the test statistic is

$$
F_{H C}=\frac{\left(R S S_{3}-R S S_{1}\right) / p(N-1)}{R S S_{1} /(N T-N(1+p)-p)} .
$$

As in the case of $\mathrm{HNC}$, if the individual effects $\alpha_{i}$ are assumed to be fixed, the ML estimator is consistent with the FE estimator.

If the $\mathrm{HC}$ hypothesis is rejected, it implies that the data generating process is non homogeneous and that no homogeneous causality relationships can be obtained. It may, however, still be possible that for one or more cross section units, causality relationships still exist. So, the third step is to test the heterogeneous non-causality hypothesis (HENC). The $F_{H E N C}$ statistic is calculated using $R S S_{l}$, obtained above, in addition to the sum of 
squared residuals $\left(R S S_{2, i}\right)$ from a model in which the slope coefficient for the panel member $i$ in question is constrained to zero. The hypotheses in this case are

$$
\begin{aligned}
& H_{o}: \exists \mathrm{i} \in[1, \mathrm{~N}] / \forall \mathrm{k} \in[1, \mathrm{p}] \beta_{i}{ }^{(k)}=0 \\
& H_{1}: \forall \mathrm{i} \in[1, \mathrm{~N}], \exists \mathrm{k} \in[1, \mathrm{p}] / \beta_{i}{ }^{\left({ }^{2}\right)} \neq 0
\end{aligned}
$$

For testing these hypotheses the following statistic is calculated:

$$
F_{H E N C}=\frac{\left(R S S_{2, i}-R S S_{1}\right) / p}{R S S_{1} /(N T-N(1+2 p)+p)} .
$$

These $\mathrm{N}$ individual tests identify the cross-section unit for which there are no causality relationships. A second test examines the joint hypothesis that there are no causality relationships for a subgroup of cross-section units. In this case, the Wald statistic is

$$
F_{H E N C}=\frac{\left(R S S_{4}-R S S_{1}\right) /(n n c p)}{R S S_{1} /(N T-N(1+p)-n c p)},
$$

where $R S S_{4}$ corresponds to the realisation of the residual sum of squares obtained in model (1) when one imposes the nullity of the $k$ coefficients associated with the variable $x_{i, t-k}$ on the $n_{n c}$ cross-section units of the subgroup. $n c$ is the number of cross-section units not belonging to the subgroup (for which $\beta$ is not constrained to 0 ).

\section{Data and regional classifications}

The data are municipality-based population data produced by Statistics Finland that have been reworked to match regional breakdowns in 2005. Annual data from 1970 onward are used. Annual data at the municipality level are available from the year 1950 onward, but these data are not reliable in the years between population censuses before the year 
1970. The establishment of the Population Register Centre in 1969 improved the reliability of population statistics during the years between population censuses.

The empirical analyses are based on the current regional breakdown, i.e., NUTS Level 3 regions and NUTS Level 4 subregions in 2005, since the aim is to analyse regional development with the help of the present-day regions and regional breakdowns as these have been shaped over the course of time. The abbreviation "NUTS" refers to the Nomenclature of Territorial Units for Statistics, which was established by Eurostat more than 30 years ago in order to provide a single uniform breakdown of territorial units for the production of regional statistics for the European Union. Finnish NUTS Level 3 regions consist of provinces or counties ("maakunta"), while NUTS Level 4 subregions ("seutukunta") are close to functional areas. Consequently, NUTS Level 4 subregions represent local labour market areas reasonably well.

There were 20 regions and 77 subregions in Finland in 2005. Subregions consist of two to thirteen municipalities and regions of two to seven subregions. One small and isolated region, Åland (the Åland Islands), which constitutes three subregions, is omitted due to its special character. Åland has political autonomy and differs from the other regions in continental Finland in many ways. As a consequence, the number of regions used in the study is 19 .

The formation of both regions and subregions, then, is based on the municipal division in 2005. The fact that during the study period a number of changes took place in the municipal division constitutes a problem in constructing the data. The number of municipalities was 432 in 2005, while it was 518 in 1970. Some municipalities have been reorganised to form larger entities, and new municipalities have been formed. All these changes need to be taken into account in the formation of the data. In cases where the entire municipality has been consolidated with another one this is easy. It is more problematic where a municipality has been divided between two or more municipalities. In these cases the population of the municipality in the period before its division is added to the municipality which received the majority of the population. In practice, the 
problems following from this are small, because in most cases such municipalities have been absorbed into the same subregion (which is the lowest level of regional unit used here).

In the analyses, a distinction between centres and peripheral regions is made. Figure 1 shows the 19 nineteen regions and their centres. The centre of a region is defined as the subregion which had the largest population in 2004. All the other subregions in the region are defined as periphery. In most cases, identifying the regional centres is obvious: the centre is a regional capital surrounded by a large local labour market, while the other subregions are much smaller, and can really be regarded as peripheral. However, some regions may have several fairly large subregions, in addition to the centre, in which cases the categorisation is not that clear. But in all cases, the leading subregion identified in this way is also the administrative centre of its region.

--Figure 1 around here--

Finland is a country small in population but large in area. Table 1 shows that many of the regions and their centres are small in population. Finland's geography and demographic features imply regional problems which are related to long distances and a scattered population. Regions are comparatively distinctive, for which reason spillovers may also remain minor. Therefore, we do not aim to employ spatial econometric approaches here. ${ }^{1}$

--Table 1 around here--

We analyse the relationships between the annual population development of the centres and peripheries in nineteen regions in 1970-2004. For both variables, we first take natural logarithms and then difference them in order to eliminate possible unit roots and to reach time stationarity. Thus, we are in fact analysing growth rates.

\footnotetext{
${ }^{1}$ To integrate a spatial econometric approach into this novel methodology - to employ Granger causality tests in a panel framework - is an interesting challenge which should be met in near future.
} 
Table 1 also shows the average annual growth rates of the nineteen centres and hinterlands in 1970-2004. In total, the population share of the centres increased from 58\% in 1970 to $67 \%$ in 2004 . There seems to be, however, considerable variation in the growth rates. Growth was fastest, $2.0 \%$ p.a., in the centre of Northern Ostrobothnia, the Oulu sub-region, while Kajaani, the centre of Kainuu, was the slowest growing centre, even showing a negative average annual growth rate of $-0.1 \%$. The average annual growth rate for all centres was $+0.6 \%$. On average, growth has been faster in large centres, but the relationship between centre size and growth is by no means clear. For example, Pori was a rather large centre in 1970 but has exhibited very slow growth. For the hinterlands, the average growth was $-0.3 \%$. There is also much variation in the hinterland growth rates, which range between $-0.9 \%$ and $+0.8 \%$. For the further analyses, we divided the regions into three categories according to the growth rates of their centres (see Table 1): regions with rapidly growing centres, regions with average growing centres, and regions with slowly growing centres.

Figure 2 shows the cross-plot of average annual growth rates in centres and hinterlands in our nineteen regions. The figure seems to show a weak positive relationship between the growth of centres and that of hinterlands. The correlation coefficient, $r=0.39$, is not, however, statistically significant. Based on this examination, it is hard to say anything about causal processes behind the growth processes in the regions.

-- Figure 2 around here --

\section{Results}

The Granger causality tests between the growth of centres and the growth of peripheries in Finland are performed for the period 1970-2004, with lags from one to three. ${ }^{2} \mathrm{We}$ follow the nested procedure described above to test different causality relationships. The tests are based on Wald statistics. In order to test the various hypotheses, we calculated

\footnotetext{
${ }^{2}$ It is also possible to consider the instantaneous case to involve possible contemporaneous effects. For robustness check, we also made these analyses (which involved the current values of $x$ as regressors). The results were consistent with the results obtained with our more conventional Granger case.
} 
the test statistics using the sum of squared residuals from the unrestricted model (1) and the sum of squared residuals from the requisite restricted models. The sums of squared residuals are obtained from the MLE, which in this case corresponds to the fixed effects estimator. To perform the estimations required, we used the constrained regression technique.

As a first step in exploring the bi-directional Granger causality between population growth in centres and in peripheries, the homogeneous non-causality hypothesis is assessed. We used up to three lag lengths. The Akaike information criterion suggested that no more lags are needed, which is confirmed by the results. The test statistics are presented in Table 2: they are statistically significant both with one and two lags, but not with three lags. In all, these results allow us to reject the homogeneous non-causality hypothesis. So for at least one region (and possibly all), there is statistical evidence of Granger causality from growth in centres to growth in peripheries, and vice versa.

Given the rejection of the HNC hypothesis, the homogeneous causality hypothesis is tested, the results of which are also shown in Table 2. The hypothesis that growth in centres causes growth in peripheries is rejected with one and two lags, but the test statistic is not significant with three lags. The opposite hypothesis, that there is causality from growth (or population changes) in peripheries to growth in centres, is clearly rejected with only one lag. With two lags, the test statistic is significant only at the $10 \%$ level and with three lags non-significant. We can, however, reject the homogeneous causality hypothesis and conclude that, in both cases, the causal process is either heterogeneous or does not exist across all the regions in our sample.

-- Table 2 around here --

The next step in an attempt to search for Granger causality is to discover the contribution of individual regions to the existence of causality, i.e., we test the heterogeneous noncausality hypotheses. The results for each region are presented in Table 3. The test statistics are calculated for one lag, since the previous results suggest lag $t-1$ to be 
strongest. The results indicate that the relationship "growth in centres Granger-causes population changes in peripheries" appears to hold for nine regions. For the remaining ten regions there is not enough statistical evidence for causality. With respect to the nine regions, an interesting question is the sign of the effect: can we find evidence in favour of backwash or spread effects in the regions in which causality from centre to the hinterland has been located? Examination of the signs of the estimated parameters $\beta_{i}$ in (1) allows us to determine the direction of the causal relationship. The results show that, of the nine significant effects, four are positive and five negative (see Table 3). Accordingly, we obtain somewhat more evidence in favour of backwash effects than spread effects. Overall, however, our results suggest that the effects of a centre on its hinterland are subject to wide variation: depending on the case, the net effects of centres are found to be either favourable or unfavourable to their hinterlands and (statistically) nil in more than half of the nineteen regions.

-- Table 3 around here --

The inverse relationship "population changes in peripheries Granges-cause changes in centres" holds for twelve regions and does not hold for seven regions. Of the twelve significant effects, two are positive and ten negative. Hence, in most regions the forecast for the growth rate in centres improves when a lagged value for population development in the periphery is taken into account. The fact that the estimated effect is negative in most regions could be interpreted as evidence of a push effect in these peripheral locations: due to weak employment and living prospects, workers are forced to leave their places of domicile, which turns out to benefit the centres. It is interesting to find that a bidirectional causality relation is observed for six regions out of nineteen. In four regions, no statistical evidence of Granger causality in either direction was found.

What are the characteristics of the regions exhibiting spread and of those exhibiting backwash? One potential explanation is related to the strength of the centre, which may have effects to the causation and its sign (cf. Partridge et al. 2008). To analyse this, we tested the significances of the rapidity of the growth and the size of the centre, which are 
both potential sources of heterogeneity. First, we tested the joint hypotheses that there are no causal relationships for the three categories according to the growth rates of their centres (Table 3). Interestingly, all the test statistics are significant, implying that growth in centres Granger-causes population changes in peripheries, and vice versa, in all three categories of regions. What is most important, however, is that the average signs of the effects are not negative for those regions with slowly growing centres, whereas they are negative in the other two categories. In these regions, a change in the growth rate in the centre has the same sign as a change in the growth rate in the hinterland, and vice versa. This suggests that slowly growing centres provide more room for the growth of their hinterlands, perhaps simply because they are weak centres. On the contrary, if a region has a rapidly growing centre - a growth centre - the centre seems to have negative effects on its hinterland. In this case, backwash effects are dominant, and people in the hinterlands are forced to move into the growth centres.

Second, we tested the joint hypotheses for three categories of regions where the categorisation is based on the size of the centre in the initial year, 1970 (Table 3). There are six regions with large centres, six with small centres, and seven with medium-sized centres. In this case as well, all the test statistics are significant, suggesting that the centre size matters. Causation runs both ways. Large and medium-sized centres have backwash effects on their hinterlands, while small centres have spread effects on their hinterlands. The inverse relationship "from hinterland to centre" is, however, negative also in this category. All in all, the test results for heterogeneous non-causality suggest that the characteristics of the centre have a bearing on the sign and size of causation: rapidly growing and large centres have backwash effects, while slowly growing centres and small centres have spread effects.

\section{Conclusions}

The new economic geography emphasises the role of endogenous agglomeration forces in creating a distinct core-periphery structure. This development is, however, counterbalanced by dispersion forces. Traditional regional economic theories predict that 
growth centres may have both spread and backwash effects on their hinterlands. Depending on the relative strengths of these effects, the net spillover effects are either positive or negative. The aim of current Finnish regional policy is to strengthen regional centres, by which it also hopes to spread growth to their hinterlands; the actual results of this policy, however, are largely unknown. Research on causal relationships between the growth of centres and peripheries in Finland has not been attempted before this study. Moreover, empirical studies on the effects of growth centres in their regions are rare. This paper addresses an important policy area that is understudied despite the large sums of money devoted to such policies.

A contribution of this study is to introduce a new approach for analysing causal processes in regional growth. In this paper, we proposed an extension of the Granger causality definition to be applied to the analysis of mutual relationships between centres and peripheries. The Granger causality test was adapted to a panel data context with the possibility of heterogeneity between regions. This is important since growth processes may differ across regions. We applied a nested testing procedure, as first proposed by Hurlin and Venet (2001), which consists of three main steps: testing the homogeneous non-causality hypothesis, testing the homogeneous causality hypothesis, and testing the heterogeneous non-causality hypothesis.

Our empirical analysis was based on the use of annual population data from nineteen Finnish regions over the period 1970-2004. The centre was defined as the largest subregion in the region, which coincided in all cases with the administrative centre of each region, while the hinterland consisted of all other sub-regions comprising the region. Centres defined in this way are clearly heterogeneous: some have grown quickly, i.e., they are real growth centres, while others have not. Our results also showed heterogeneity in the relationships between the growth of centres and their hinterlands. We were able to reject both the homogeneous non-causality hypothesis and the homogeneous causality hypothesis. Thus we reached an important result according to which causal processes are heterogeneous in regions. Causality from centres to peripheries was found for nine regions, and causality from peripheries to centres for twelve regions. A bi-directional 
causality relation was observed for six regions. In four regions, we could find no statistical evidence of Granger causality in either direction. There was also much fluctuation in the signs and sizes of the effects. More evidence was found for backwash effects than for spread effects. In particular, if a regional centre has grown rapidly or if it is a large centre, it has generally had negative effects on its hinterland. This implies that the aim of current Finnish regional policy - to strengthen regional centres in order to balance development within regions - does not seem to be leading to the desired results, although it may help in preventing growth from becoming concentrated in only a handful of large cities. 


\section{References}

Baltagi, B.H. (2005) Econometric analysis of panel data, New York, Wiley.

Dixon, R.J \& Thirlwall A.P. (1975) A model of regional growth rate differentials along Kaldorian lines, Oxford Economic Papers, 27, 201-214.

Erdil, E. \& Yetkiner, I.H. (2008) The Granger-causality between health care expenditure and output: a panel data approach, Applied Economics, 40 (forthcoming).

Fujita, M. (2007) Towards the new economic geography in the brain power society, Regional Science and Urban Economics, 37, 482-490.

Fujita, M., Krugman P. \& Venables A.J. (1999) The spatial economy-Cities, regions, and international trade, Cambridge, The MIT Press.

Granger, C.W.J. (1969) Investigating causal relations by econometric models and crossspectral methods, Econometrica, 37, 424-438.

Henry, M.S., Barkley \& D.L., Bao, S. (1997) The hinterland's stake in metropolitan growth: evidence from selected southern regions, Journal of Regional Science, 37, 479-502.

Henry, M.S., Schmitt, B. \& Piguet, V. (2001) Spatial econometric models for simultaneous systems: application to rural community growth in France, International Regional Science Review, 24, 171-193.

Hirschman, A. (1958) The strategy of economic development, New Haven, CT, Yale University Press.

Holtz-Eakin, D., Newey, W. \& Rosen H. (1988) Estimating vector autoregressions with panel data, Econometrica, 56, 1371-1395.

Hood III, M.V., Kidd, Q. \& Morris, I.L. (2008) Two sides of the same coin? Employing Granger causality tests in a time-series cross-section framework, Political Analysis, 16, 324-344.

Hsiao, C. (1986) Analysis of panel data, Cambridge, Cambridge University Press.

Hurlin, C. \& Venet, B. (2001) Granger causality tests in panel data models with fixed coefficients: Mimeo, University of Paris IX.

Hurlin, C. \& Venet, B. (2005) Testing for Granger causality in heterogeneous panel data models, Revue Economique, 56, 1-11. 
Kaldor, N. (1970) The case for regional policies, Scottish Journal of Political Economy, $18,337-348$.

Krugman, P. (1991) Increasing returns and economic geography, Journal of Political Economy, 99, 483-499.

Krugman, P. (1998) What's new about the new economic geography, Oxford Review of Economic Policy, 14, 7-17.

Myrdal, G. (1956) Economic theory and under-developed regions, London, Duckworth.

Nickell, S. (1981) Biases in dynamic models with fixed effects, Econometrica, 49, 13991416.

Parr, J.B. (1999a) Growth-pole strategies in regional economic planning: a retrospective view. Part 1 - Origins and advocacy, Urban Studies, 36, 1195-1215.

Parr, J.B. (1999b) Growth-pole strategies in regional economic planning: a retrospective view. Part 2 - Implementation and outcome, Urban Studies, 36, 1247-1268.

Partridge, M., Bollman, R.D., Olfert, M.R. \& Alasia, A. (2007) Riding the wave of urban growth in the countryside: spread, backwash, or stagnation? Land Economics, 83, 128152.

Partridge, M.D., Rickman, D.S., Ali, K. \& Olfert, M.R. (2008) Lost in space: population growth in the American hinterlands and small cities, Journal of Economic Geography, $8,727-757$.

Perroux, F. (1950) Economic space: theory and applications, Quarterly Journal of Economics, 65, 89-104.

Pred, A. (1966) The spatial dynamics of U.S. urban-industrial growth, Cambridge, The MIT Press.

Richardson, H.W. (1978) Regional and urban economics, New York, Penguin.

Schmitt, B. \& Henry, M.S. (2000) Size and growth of urban centres in French labor market areas: consequences for rural population and employment, Regional Science and Urban Economics, 30, 1-21.

Tervo, H. (2005) Regional policy lessons from Finland, in Felsenstein, D., Portnov, B.A. (Eds.). Regional Disparities in Small Countries, Berlin, Springer-Verlag. 
Tervo, H. (2008) Does the new economic geography tell the right story? Long-term regional development and the role of growth centers in Finland. A paper presented at the RSAI World Congress, Sao Paolo, March 17-19, 2008. 
Table 1. Average annual growth rates of population in centres and hinterlands, 1970-2004

\begin{tabular}{|c|c|c|c|c|c|}
\hline \multirow[t]{2}{*}{ Centre } & \multirow[t]{2}{*}{ Region } & \multicolumn{2}{|c|}{ Population of the regional centre in 1970} & \multicolumn{2}{|c|}{ Average annual growth rate in $1970-2004, \%$} \\
\hline & & $\begin{array}{l}\text { Number } \\
(1000 s)\end{array}$ & $\begin{array}{l}\text { Percent of the region's } \\
\text { population }\end{array}$ & Centre & Hinterland \\
\hline \multicolumn{2}{|c|}{ Category I - regions with rapidly growing centres } & 1433 & 65,4 & +1.3 & -0.2 \\
\hline Oulu & Northern Ostrobothnia & 121 & 40,2 & +2.0 & -0.1 \\
\hline Helsinki & Uusimaa & 820 & 89,4 & +1.4 & +0.8 \\
\hline Porvoo & Itä-Uusimaa & 52 & 71,8 & +1.2 & -0.3 \\
\hline Tampere & Tampere Region & 229 & 57,3 & +1.1 & -0.4 \\
\hline Jyväskylä & Central Finland & 122 & 49,4 & +1.0 & -0.5 \\
\hline Kuopio & Northern Savo & 90 & 34,7 & +0.9 & -0.6 \\
\hline \multicolumn{2}{|c|}{ Category II - regions with average growing centres } & 680 & 50,9 & +0.6 & -0.1 \\
\hline Turku & Southwest Finland & 227 & 59,0 & +0.9 & -0.0 \\
\hline Seinäjoki & South Ostrobothnia & 50 & 25,3 & +0.9 & -0.4 \\
\hline Rovaniemi & Lapland & 52 & 26,2 & +0.6 & -0.4 \\
\hline Kokkola & Central Ostrobothnia & 45 & 70,4 & +0.5 & -0.1 \\
\hline Lahti & Päijät-Häme & 148 & 82,1 & +0.4 & -0.3 \\
\hline Vaasa & Ostrobothnia & 79 & 49,2 & +0.4 & +0.1 \\
\hline Hämeenlinna & Häme & 80 & 52,6 & +0.3 & +0.3 \\
\hline \multicolumn{2}{|c|}{ Category III - regions with slowly growing centres } & 547 & 52,1 & +0.0 & -0.6 \\
\hline Lappeenranta & South Karelia & 63 & 43,6 & +0.3 & -0.6 \\
\hline Joensuu & Northern Karelia & 109 & 58,7 & +0.2 & -0.9 \\
\hline Pori & Satakunta & 137 & 58,6 & +0.0 & -0.1 \\
\hline Kouvola & Kymenlaakso & 101 & 50,8 & -0.1 & -0.3 \\
\hline Mikkeli & Etelä-Savo & 75 & 40,6 & -0.1 & -0.5 \\
\hline Kajaani & Kainuu & 61 & 60,9 & -0.1 & -0.9 \\
\hline All regions & & 2660 & 58,1 & +0.6 & -0.3 \\
\hline
\end{tabular}


Table 2. Test results for homogeneous non-causality (HNC hypothesis) and homogeneous causality (HC hypothesis)

\begin{tabular}{lll}
\hline Lags & $F_{H N C}$ & $F_{H C}$ \\
\hline Causality from centre to hinterland & & \\
Lag 1 & $7.502^{* * * *}$ & $5.353^{* * *}$ \\
Lag 2 & $1.989^{* * *}$ & $2.050^{* * *}$ \\
Lag 3 & 1.178 & 1.240 \\
\hline Causality from hinterland to centre & & \\
Lag 1 & $7.259^{* * *}$ & $6.420^{* * *}$ \\
Lag 2 & $1.789^{* * *}$ & $1.417^{*}$ \\
Lag 3 & 0.651 & 0.620 \\
\hline
\end{tabular}

*** Reject of Ho at $1 \%$ level of significance

** Reject of Ho at $5 \%$ level of significance

* Reject of Ho at $10 \%$ level of significance 
Table 3. Test results for heterogeneous non-causality (HENC hypotheses, lag 1)

\begin{tabular}{|c|c|c|c|c|}
\hline \multirow{2}{*}{ Region } & \multicolumn{4}{|c|}{ Causality } \\
\hline & \multicolumn{2}{|c|}{$\begin{array}{l}\text { From centre to hinterland } \\
F_{H E N C} \text { Sign of the effect }\end{array}$} & \multicolumn{2}{|c|}{$\begin{array}{l}\text { From hinterland to centre } \\
F_{H E N C} \text { Sign of the effect }\end{array}$} \\
\hline Uusimaa & 0.01 & & $7.79 * * *$ & - \\
\hline Itä-Uusimaa & $2.85 *$ & + & 0.06 & \\
\hline Southwest Finland & 2.31 & & $8.13 * * *$ & - \\
\hline Satakunta & $4.74 * *$ & + & $3.82 *$ & + \\
\hline Häme & 0.58 & & 0.26 & \\
\hline Tampere Region & 0.60 & & $8.36 * * *$ & - \\
\hline Päijät-Häme & 0.04 & & 1.62 & \\
\hline Kymenlaakso & $4.19 * *$ & - & 0.80 & \\
\hline South Karelia & 0.24 & & $4.24 * *$ & - \\
\hline Etelä-Savo & 2.43 & & 2.42 & \\
\hline Northern Savo & 0.00 & & $6.12 * *$ & - \\
\hline Northern Karelia & $2.96 *$ & + & $4.34 * *$ & + \\
\hline Central Finland & $10.55 * * *$ & - & $9.65 * * *$ & - \\
\hline Southern Ostrobothnia & $4.10 * *$ & + & 0.36 & \\
\hline Ostrobothnia & $9.01 * * *$ & - & $20.89 * * *$ & - \\
\hline Central Ostrobothnia & 0.13 & & $5.21 * *$ & - \\
\hline Northern Ostrobothnia & $15.78 * * *$ & - & $29.25 * * *$ & - \\
\hline Kainuu & 0.75 & & 0.00 & \\
\hline Lapland & $68.44 * * *$ & - & $30.14 * * *$ & - \\
\hline $\begin{array}{l}\text { Regions with rapidly } \\
\text { growing centres }\end{array}$ & $4.98 * * *$ & - & $9.65 * * *$ & - \\
\hline $\begin{array}{l}\text { Regions with average } \\
\text { growing centres }\end{array}$ & $12.801 * * *$ & - & $8.32 * * *$ & - \\
\hline $\begin{array}{l}\text { Regions with slowly } \\
\text { growing centres }\end{array}$ & $2.66 * *$ & + & $2.55 * *$ & $(+)$ \\
\hline $\begin{array}{l}\text { Regions with large } \\
\text { centres }\end{array}$ & $3.16 * * *$ & - & $6.70 * * *$ & - \\
\hline $\begin{array}{l}\text { Regions with medium- } \\
\text { sized centres }\end{array}$ & $5.21 * * *$ & - & $9.18 * * *$ & - \\
\hline $\begin{array}{l}\text { Regions with small } \\
\text { centres }\end{array}$ & $14.93 * * *$ & + & $7.23 * * *$ & - \\
\hline
\end{tabular}


Figure 1. The nineteen Finnish regions and their centres

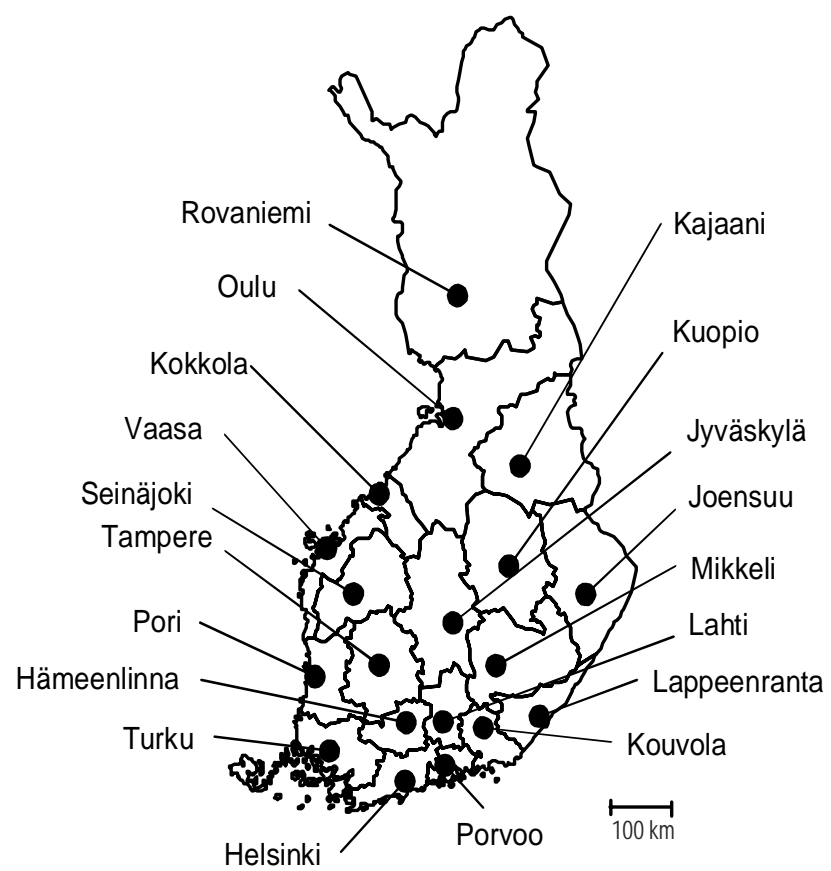


Figure 2. Average annual growth rates (\%) in centres and peripheries (1970-2004)

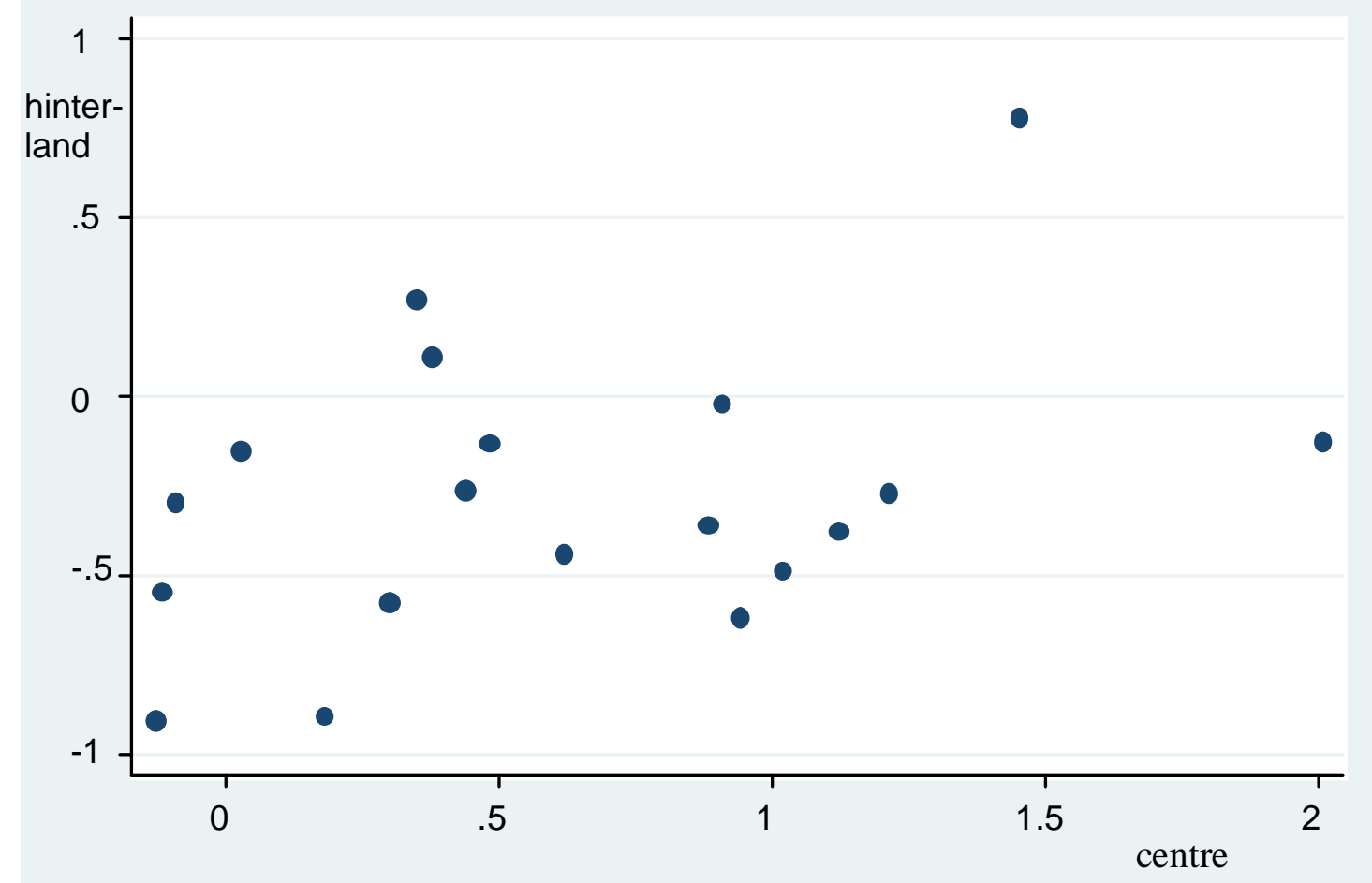

